\title{
Digital Diversity
}

\section{Strategies and Competencies for Diversity-Sensitive Teaching and Learning in Digital Times}

\author{
DAVID KERGEL
}

\begin{abstract}
Digital teaching and learning and diversity-sensitive teaching are often researched independently. This can quickly lead to overlooking the common origin of digitization (or early Internet culture) and an emancipatory diversity-sensitive stance. Uncovering the common origin in the emancipation movements at (US) universities in the 1960s to the early 1980s allows for practical consequences for a diversity-sensitive use of digital media in educational contexts. To accomplish this, the presentation is divided into three steps. In the first step, the development of a diversity-sensitive attitude will be reconstructed, and in the second step, the development of early Internet culture. Based on this genealogical reconstruction work, a competence model for a diversity-sensitive use of digital media in educational contexts will be presented.
\end{abstract}

KEYWORDS: Digital teaching; diversity-sensitive teaching; competence model for a diversity-sensitive use of digital media; internet culture

\section{Introduction}

Education reflects how we deal with societal challenges and prepares learners to deal with these challenges appropriately. This task profile requires that education also identifies societal demands and develops strategies for dealing with these challenging strategies. The article contributes to this. For this purpose, a theoretically based competence model for diversity-sensitive teaching and learning in higher education is introduced. This competence model uses integrative digital media. With this integrative use of digital media for diversity-sensitive teaching in higher education, a synthesis between diversity and reflective use of digital media is developed. 


\section{Diversity as a twofold challenge for teaching}

Two discourse formations, in particular, make the question of an appropriate approach to diversity in higher education a relevant topic. High-quality teaching cannot do without an appropriate, i.e., appreciative and respectful, approach to diversity.

The handling of diversity in higher education makes the questions of exclusion and inclusion in the teaching process also questions of higher education didactics. In other words: In the course of the shift from teaching to learning in the Bologna Process the quality of university teaching is moving into the focus of the discourses of self-understanding in higher education.

In 1998 the so-called Sorbonne-Declaration had been signed by the education ministers of France, Germany, Great Britain and Italy. The Sorbonne-Declaration formulated the goal to harmonize the architecture of the European higher education system. In 1999, 29 other countries joined the declaration. The initiation phase of the Bologna process had started and took place in a time when the Learning Management Systems were increasingly implemented at universities.

Since then the Bologna process and E-Learning had inscribed themselves in German universities. In the course of this lasting change of German universities, an interlinking between E-Learning and the Bologna process emerged: In 2001 the European Association of Distance Teaching Universities (EADTU) discussed possible synergy effects between E-Learning at universities and the Bologna process. The programmatic text "Communication of Madrid about virtual higher education and the Bologna process" states that E-Learning "will contribute to the Bologna aims of mobility, broad access to higher education and competence development in a context of lifelong learning" (EADTU, 2001, para 7).

The interlinking between digital Learning and the Bologna process is symbolic represented in the term 'eBologna'. This term was discussed and coined at the Bologna follow-up conference in 2005 - in times when a Web 2.0-based E-Learning increasingly unfolded. A basic assumption of eBologna can be summarized as follow:

- One central aim and feature of the Bologna process is to harmonize the architecture of the European higher education system.

- Digitally supported learning and teaching enable decentralized learning and teaching processes which are detached from spatial and temporal constraints.

- The merge of both approaches enables a constructive perspective on a virtual European educational space (cf. Handke, 2005, p. 36).

In addition to this linking of digital transformation and the Bologna Process, the linking of diversity sensitivity and the Bologna process also increases discursive relevance (cf. Kergel \& Heidkamp 2019): An appropriate discussion of higher education teaching requires that the teaching process be considered in its complexity. This also includes:

- the reflection of hierarchies and dependencies in higher education as well as

- reflecting on the potential for exclusion that results from a careless approach to diversity in higher education teaching.

Reflecting on heterogeneity in teaching makes it possible to deal with socially coded hierarchies and relationships of dependency in an understanding-analytical way, which can also unfold metonymically in the teaching process.

From a value-oriented perspective, higher education can become a space for cultural encounters and inclusion. Following Derrida, it could be formulated that the university becomes a central actor in civil society by living diversity-sensitive inclusion in the digital age:

Following Derrida (2002), we can think of the 'unconditional university' as a space where the societal meaning of digital media can be questioned and diversity can be discussed. 
Here then is what I will call the unconditional university or the university without condition: the principal right to say everything, whether it be under the heading of fiction and the experimentation of knowledge, and the right to say it publicly, to publish it. (Derrida, 2002, p. 26)

The university "should remain an ultimate place of critical resistance - and more than critical - to all the powers of dogmatic and unjust appropriation" (Derrida, 2002, p. 25f.). Derrida's concept of the unconditional university makes critical reflection, here analyzing the digital turn and diversity of society. At the same time, the university is an educational institution: as such it is tasked with educating skilled workers. In the interest of students' employability, higher education has to meet the challenge of ensuring that they acquire the media skills required for professional life in the Digital Age and a plural society.

It is precisely the interplay between theoretical foundation and an application-oriented approach that opens up a discursive sphere. The reflections for action strategies of diversitysensitive teaching establish a dialogical space: Diversity-sensitive teaching can therefore also be understood as part of a dialogue that all actors involved in higher education teaching can or should conduct: Especially in times, in which:

- the concept of culture is increasingly contested,

- $\quad$ social diversity is a topic of right-wing populist positions and thus

- the discrimination of diversity is becoming more and more socially acceptable and coherent cultural or national identity is discursively reactivated and sacralized

University can be thought of as a space of emancipative knowledge production and as valueoriented social inclusion. Digital media make it possible to include the diversity of university teaching in a dialogical way in the teaching/learning process. To develop and substantiate this thesis, I will first develop the underlying understanding of diversity to relate it to the educational potential of digital media in higher education contexts.

\section{Diversity - approaching a complex concept}

Although the diversity discourse young in Germany is met with an enormous response (cf. Hahm 2015, p. 8). Thus, according to Kaufmann, a "hype" (Kaufmann 2016, p. 83) can be stated, with which diversity has advanced to a central, civil-historical topic that everyone has to face. However, in contrast to the discursive power of the concept, a definition of the term seems to be complicated. On the one hand, the term has been defined as a "buzzword", i.e. a fashionable word. Yet, at the same time, the term diversity is also difficult to specify due to its multiperspective and deliberate openness.

Accordingly, Walgenbach (2014) understands diversity as a travelling concept: diversity can be interpreted differently in different disciplinary and international contexts and thus make different contributions to social self-understanding discourses. From this perspective, Diversity can be defined as a critical approach to cultural and ethnic differences or constructions of difference. In the course of the German-language discussion of diversity, a distinction can be made between diversity management and a power-critical approach to diversity.

This ambivalence of the meaning of the term diversity gives rise to a tension that shapes the conceptual definitions of diversity. Thus, on the one hand, a profit-oriented or "marked based" diversity management can be identified. This "marked based" approach to diversity refers to the economic efforts within large international companies to use diversity to become more "efficient

The semantics of a diversity understanding in terms of "marked efficient management contrasts with a power-critical diversity understanding. The power-critical understanding of diversity can be located in conceptual proximity to the approach of inclusion (di Blasi 2016, p. 29). From a power-critical perspective, diversity can be understood as a theory-practice approach 
that makes it possible to overcome processes of exclusion in favour of an inclusive social practice via diversity sensitivity (cf. Heidkamp \& Kergel 2018).

While diversity management essentially addresses the harnessing of diversity in corporate and market logic (cf. Kergel 2019), a power-critical understanding of diversity problematizes exclusion dynamics, hierarchies, and dependency relations based on cultural, ethnic, and similar constructions of difference.

Power-critical diversity approaches see social identities as effects of domination structures such as racism, anti-Semitism, heteronormativity, etc. Power-critical diversity analyses work out how identity patterns emerge from discursive assignment practices. The starting point is considering that "diversity is a dynamic construction of differences- of "doing diversity" (Linde 2018, p. 140). Diversity-sensitive reflections also implicitly adopt an objective concept of truth with the notions of given identity patterns: instead of determining identity patterns based on fixed characteristics, an analysis of the discursive production of identity patterns is undertaken. Thus, "questions about the production processes of difference (difference practices) and their effectiveness for social realities" (ibid.) come into analytical view. The theoretical added value of such a perspective lies in the praxeological perspective on identity: identity patterns or phenomena are produced through a "'"doing difference" (cf. West \& Fenstermaker 1995) or a "doing diversity.

This power-critical understanding of diversity can be connected to the communication potentials of digital media. A genealogical reconstruction reveals that a power-sensitive understanding of diversity and the discursive framing of the media specificity of the digital show central overlaps in their genesis.

From a power-critical perspective, diversity can be understood as a demand for participation and recognition of diversity. These demands were powerfully formulated in the course of the protest movements of the postwar period (Salzbrunn 2014, p. 28). These movements influenced science and politics and created a growing awareness of difference - and the associated processes of discrimination. In other words: The concept of diversity can be analyzed as an effect of civil society, socio-cultural emancipation movement. This thesis can also be illustrated by the discursive establishment of the term diversity:

Thus, diversity as a term first became judicially relevant in 1978: in a lawsuit of Regents of the University of California vs Bakke. The most prominent U.S. universities defended the advancement of minorities (defined by race). This sensitivity to minorities on the part of universities was evident, among other things, in so-called "affirmative action programs."

Through the affirmative action programs, which President John F. Kennedy established in 1961, structural discrimination against minorities was countered by affirmative action in educational institutions and businesses.

Under these affirmative action programs, members of disadvantaged or underrepresented groups were promoted. This particularly benefited women and/or Native Americans. This process paradigmatically reveals an ambivalence of the term diversity. Thus, diversity aims at valuing social group characteristics. Accordingly, diversity refers to aspects such as ethnicity, class, gender, physical ability, or socioeconomic background". These minorities were given preference over representatives of the majority in the allocation of university places. Consequently, single actors of the majority were excluded. This ambivalence led to the judicial dispute "California vs Bakke". This legal dispute arose from the lawsuit filed by white student Allan Bakke who sued the University of California for discrimination in 1974. In the trial, which was intensely covered by the media, the Supreme Court finally affirmed in 1978 that affirmative action policies in the United States were constitutional. When diversity is defined as valuing diversity and diversity is defined in terms of a variety of categorically ascertainable 
characteristics, the risk of exclusion and inclusion dynamics remains, as the case of California $\checkmark$. Bakke paradigmatically demonstrates.

For example, if People of Color (POC) are recognized but not wheelchair users, a PoC in a wheelchair will receive recognition. For instance, if PoC and wheelchair users are identified but not transgender people, a transgender PoC in a wheelchair will not find recognition. Before defining what marginal group exists, an inclusive and indifferent attitude towards all people should be taken.

In other words, or poststructuralist thought: Through the dynamics of binary category designations, minorities are identified, and these groups have to be recognized: Women achieve equality, while transgender people do not. This logic produces the exclusion of actors who do not fit into the conceptual framework by which the identified minorities are defined.

Consequently, an iterative process of de-solidarization occurs that separates minorities from each other: the women's movement distanced itself from lesbians as they became more socially accepted to be better able to connect to the majoritarian conceptual inventory. The same was repeated when gays and lesbians distanced themselves from people who understood themselves as transgender.

To conceptualize the acknowledgement of minorities coherently and live it in practice, an understanding of diversity is needed that overcomes thinking in categories. Thinking in categories denotes the priority of categories over the individual. People exhibit categories and are subordinated to these categories. For example, if a person cannot see, he is blind and disabled. A human being beyond categories would reverse this relationship. A person who cannot see has a different way of perceiving the world than one who can see. He is not a blind sonder, defined in his perception of the world by his lack of sight. Consequently, he is not reduced to the state of being blind.

Thinking beyond categories perceives the categories. These help to understand the human being and his abilities as far as needs better. However, the human being is not reduced to a category. One approach to overcoming a binary or categorical understanding of difference lies in analyzing social categories of belonging as social constructions in terms of "doing difference". In this context, it is crucial to reflect:

- how people are reduced to categorical representations through acts of assignment, and

- how exclusion and suffering are generated in this way.

For example, questions such as the problematization of "identitarian-fixated cultural affiliations" (cf. Turkmen 2008, p. 31) become the focus of power-critical diversity analyses. Such an understanding of diversity is characterized by a "beyond essentializing, social categories of belonging" and requires, as a first step, a critical-reflexive examination of identity patterns:

- How are social affiliations produced?

- And how can these social affiliations be undermined?

A power-critical understanding of diversity can be applied to pedagogical contexts such as higher education teaching. Especially in higher education, there is a specific form of knowledge production. A power-critical diversity-sensitive perspective of university learning addresses students as social actors who can critically reflect their own socio-economically and socioculturally identity patterns within their learning process - in the sense of action research. Moreover, in a society that sees itself as knowledge-based, the appropriation of scientific knowledge provides a possibility for the emancipation of the subject.

In an understanding of science in the sense of the Enlightenment, man is not at the mercy of the world. He can explain the world, identify logic and irrational structures and react to 
them. Thus, irrational hierarchies and dependencies can be identified and deconstructed through scientific reflection.

Through the production of scientific knowledge, the individual acquires the authority of a critically reflexive instance of knowledge (cf. Kergel 2011), which is not at the mercy of society and its processes of inclusion and exclusion without reflection. Scientific scepticism opens up the possibility for the individual to distance itself from social categories and leads to a powercritical understanding of diversity. One way to achieve this emancipation through research competence is diversity-sensitive research-based teaching.

Employing a competence model, it is possible to make diversity-sensitive approaches usable for higher education. Using a competence model, the demanding identity analyses of a power-critical understanding of diversity can be operationalized for the field of action of university teaching. The different abilities and skills (thus a paraphrasing of the term competence) can be differentiated for the various fields of higher education teaching. With reference to Hohm (2015), a competence model for power-critical and diversity-sensitive university teaching is proposed in the following: self-competence, social competence, subject competence, and methodological competence. ${ }^{1}$ These dimensions are briefly outlined below.

\section{A competency model for diversity-sensitive Teaching}

\section{Self-competence}

With reference to Hohm, self-competence is defined by the perception and significance of one'sone's diversity and the individual reflection of one's interaction with students and their diversity (cf. Hahm 2015, p. 19). In other words, self-competence is characterized by reflections on one's bias structure. Through this critical reflection, one's own truth claims/beliefs/taste judgments, etc., can be bracketed. This makes it possible to open up to other life models and the heterogeneous lifeworld's of students, other teachers, etc., in a way that is sensitive to differences. From the perspective of higher education, there is the possibility to become aware of "opportunities and barriers of diverse target groups (cf. Hahm 2015, p. 18). Through a diversity-sensitive self-competence, action strategies can be developed to enable diversity-sensitive learning spaces. In summary, self-competence leads to a diversity-sensitive world and self-reflection that enables one to recognize the constructed-ness of social identities. The appearance of the "immutability" of social categories can thus be bracketed in a reflective-critical way.

\section{Social competence}

Social competence applies this form of difference-sensitive reflection to the social contexts of university teaching. This implies that teachers must be sensitive to group processes, their heterogeneity, and possible conflict areas (cf. Hahm 2015, p. 19). For university teaching, the goal orientation of such diversity-sensitive social competence lies in promoting an appreciative culture of discussion and cooperative collaboration that includes all participants and encourages communication and interaction free of discrimination (cf. Hahm 2015, p. 19.).

\section{Professional competence}

Professional competence entails diversity-related expertise. This includes a basic understanding of what is meant by diversity (cf. Bouffier et al. 2014, p.61). This basic understanding or

1 'Since the 1970s, the concept of competence has become increasingly established in pedagogical discourses.' The concept of competence refers to abilities and skills that make it possible to deal successfully with challenging situations. However, a power-analytic critique of the concept of competence has also been raised. Thus, the concept of competence was accused of forcing a feasibility pedagogy and ignoring power relations (Kergel \& Heidkamp 2019). 
diversity-related expertise should be reflected regarding one's subject concerning possible stereotypes or discrimination (cf. Hahm 2015, p. 18). In addition, professional competence includes knowledge about (higher education) policy objectives and measures with regard to diversity management, equal opportunities and anti-discrimination (cf. Hahm 2015, p. 18).

\section{Methodological competency}

These competence dimensions unfold dialectically in methodological competence.

The method can be defined here as the way of teaching design. Self-competence, social competence and professional competence are integrated into the teaching methods. For this purpose, teaching/learning forms must be developed that make it possible to adequately meet the requirements of personal, social and professional competence. It is advisable to use participative, collaborative teaching formats to dissolve individual restrictions in a dialogue. Thus, Lummerding (2014) advises university didactic strategies that expand the possibilities of thinking (cf. Lummerding 2014, p. 55). It is essential that university teaching not be reduced to the transmission of given knowledge but rather to be understood as contingent knowledge production. According to Derrida's concept of the unconditional university, teaching and learning have the goal of mediating critical thinking strategies. In higher education, the unconditional university manifests itself in learning which enables students to develop a critical attitude towards 'the powers of dogmatic and unjust appropriation' by scholarly means (Derrida, 2002, p. $25 \mathrm{p}$.). University teaching can be considered an open-ended and inconclusive process of negotiating a multitude of different positions and interests, to the shaping and effect of which all participants contribute decisively (cf. Lummerding 2014, p. 48).

In concrete terms, this can be linked to the "new forms of teaching" (Bouffier 2015, p. 61), such as problem-based or research-based learning. These forms of teaching/learning rely on constructivist student participation. They are based on the assumption that students construct knowledge on their responsibility and in a self-directed, intrinsically motivated manner and dialogically with each other. The collaborative, dialogical orientation of these forms of teaching makes it possible for a variety of perspectives to be taken on teaching subjects due to the diversity of the students. The resulting multi-perspectivity makes it possible to overcome limitations that result from an identity-specific point of view. In the dialogical exchange, these individual knowledge stocks get into motion, new forms of knowledge emerge. The specificity of digital mediality, i.e. the specific way of digital information production and mediation, enables individual restrictions to dissolve in a dialogue.

\section{A Genealogical Perspective on early diversity-sensitive Internet Culture}

From a genealogical perspective, it is interesting to note that the same cultural climate shaped early U.S. Internet culture as the unfolding of the divisiveness understanding. This thesis will be presented in the following before the specificity of digital media in the context of powercritical divergent-sensitive teaching is integrated.

The development of the Internet is much like the unfolding of diversity in a time of civil society transformations. On behalf of the U.S. Department of Defense, the so-called Advanced Research Products Agency (ARPA) was founded in 1958 against the 'Sputnik Shock' background. As part of ARPA's work, the so-called ARPA-Net was developed, in which (small) data packets could be sent back and forth by networking computers. Joseph Licklider, formerly a psychologist and computer scientist at the Massachusetts Institute of Technology (MIT), emphasized the interaction between computers within ARPA from 1962 onwards and recruited 
several scientists from leading universities such as Standford University and the University of California, Berkeley for this purpose.

The first connection between two mainframe computers was realized at universities in 1969. Initially, computers were connected between the University of California (UCLA), the Standford Research Institute (RSI), and Utah. The first message between these university computers was exchanged on October 29, 1969: At 10:30 p.m., a computer at the University of California sent the message "Io" to a computer at the Standford Research Institute, $600 \mathrm{~km}$ away. The network grew steadily, and by 1971 it consisted of 14 "nodes". The following came to development of decentralized digital communication, which was opened in 1990 for commercial purposes.

From a genealogical perspective, it should be emphasized that the development of the Internet and Internet culture gives characteristics of a power-critical understanding of diversity. Two paradigmatic examples of this are given below.

The Hacker Manifesto - or The Internet as Space "without skin colour, without nationality, without religious bias".

In 1986 the hacker "The Mentor'Mentor' alias Loyd Blankenship formulated the "Hackermanifesto - The Conscience of a Hacker". The hacker manifesto was published in the underground magazine "Phrack". In the hacker manifesto, the Internet is staged as a power-free counterworld to the material-physical world:

And then it happened... a door opened to a world... rushing through

the phone line like heroin through an addict's veins, an electronic pulse is

sent out, a refuge from the day-to-day incompetencies is sought... a board is

found.

""This is it... this is where I belong... "

I know everyone here... even if I've never met them, never talked to

them, may never hear from them again... I know you all... (The Mentor 2004, para. 9).

The description of the experience of the counter-world uses the semantics of the discourses around drug experimentation that emerged in the course of the protest culture of the 1960s and 1970s. The new world offers a new form of community as a home. The Mentor sees the ideals of freedom of the Internet beyond social categories of belonging: "We exist without skin colour, without nationality, without religious bias.... and you call us criminals" (The Mentor 1986, para. 12). The Internet is conceived as a space of freedom that does not recognize any social affiliation characteristics. The Internet is portrayed similarly in the "Declaration of the Independence of the Cyberspace" published in 1996.

The "Declaration of the Independence of Cyberspace" - or a Space beyond "race, economic power, military force, or station of birth".

The "Declaration of the Independence of Cyberspace" criticizes state access to the Internet. The specific reason for the publication of the Declaration of Independence of the Internet was the Telecommunications Act passed by the U.S. government in 1996. In addition to deregulation resolutions in radio and television and mobile and fixed network companies, the law contained an amendment with the "Communication Decency Act", which referred to content published on the Internet. This amendment was intended to make it possible to regulate and 
control pornography on the Internet more closely by, among other things, prohibiting the posting of indecent and "obviously offensive" content. Critics complained that this would lead to Internet censorship. The "Declaration of the Independence of Cyberspace" was published by Barlow as co-founder and representative of the Electronic Frontier Foundation (EFF). As a representative of the EFF, Barlow acted as a representative of an NGO that advocates for fundamental human rights in the age of the Internet. In the context of the "Declaration of the Independence of Cyberspace," Cyberspace is staged as a counter-world to the established power structures of the material-physical world. The Declaration of Independence opens with the words: "Governments of the Industrial World, you weary giants of flesh and steel, I come from Cyberspace, the new home of Mind. On behalf of the future, I ask you of the past to leave us alone. You are not welcome among us. You have no sovereignty where we gather" (Barlow 1996, para. 1). The post-nationalist space of freedom in Cyberspace is thereby defined by traditional

Cyberspace is characterized by its "own" culture and ethics (Barlow 1996, para. 4). Barlow locates this culture or world of Cyberspace beyond social categories of belonging such as "race, economic power, military force, or station of birth" (Barlow 1996, para. 7).

With the disappearance of social categories of belonging, new forms of communication were established, which Barlow describes as " a standing wave in the web of our communications" (Barlow 1996, para. 6). Just as there are no social affiliations, there is also no place and thus no hierarchies from which to speak: "Ours is a world that is both everywhere and nowhere, but it is not where bodies live" (Barlow 1996, para. 6).

This de-localization of communication can be analyzed with the specificity of digital media. The specificity of digital media, in turn, enables diversity-sensitive communication. Digitalbased diversity-sensitive communication can, in turn, be integrated into the competence model of power-critical diversity-sensitive teaching.

\section{Specifics of digital media}

The potential of digital media can be illustrated by distinguishing it from television. The television is a classic "unidirectional medium": Information is sent from a sender (the TV) to a mass of receivers (the viewers). This unidirectional communication is reminiscent of past times of teacher-centred frontal teaching. When everything is silent, and only one person speaks, this is called teaching. Digital media, on the other hand, enable what is known as poly-directional communication: potentially, anyone can communicate with anyone. Digital media make it possible for everyone to send information to everyone else and respond to this information in turn. In other words, the medial structure of television is the monologue. The medial structure of digital media is dialogue.

Closely related to poly-directionality is the notion of polyphony. With monologuing television, only the broadcaster has a voice. With digital media, potentially everyone has a voice. The digital world is a world full of voices or a polyphonic world. These voices are networked decentrally.

Decentralized here means that the network has no centre. At the same time, a network does not have to be closed: Through the Internet, it is possible for people to network with each other. In other words: Decentralized poly-directionality and polyphony represent the media structure of digital media.

Unlike book, these features of digital communication enable collaborative learning: It seems that books can never fully resolve the unidirectional structure. Roland Barthes writes in $S / Z$ that the original text can be expanded through one's own notes on the book. However, 
this still requires a reader to read and relate to these notes and the overall act. The dynamic of collaborative cognition is not achieved in this way. Ideally, this is characterized by a fluid interplay of producing and receiving. This fluid interplay finds its medial equivalent in the ephemeral structure of digital media. This thesis can be elaborated with reference to the meaning of the word collaborative. The word "'collaborative"'" (from the Latin word "'collaborate"'"/ can be translated as "'to work together"'".

Digital media can be used to work collaboratively in teaching/learning processes. Collaborative work is distinguished from cooperative labour.

- A division of labour characterizes cooperative work. Thus, the individual task parts are worked on by individual learners and joined together at the end. Experience has shown that learners often use this strategy in group presentations and other group work. Although this seems to be efficient, it often reduces the results because there is no dialogical discussion of the work results.

- In collaborative work, a dialogical discussion takes place at every step of the work. Especially dialogical collaboration usually leads to high-quality work results and increases the quality of the learning experience (Kergel/Heidkamp 2015).

Dialogic/collaborative collaboration can be realized in a low-threshold and flexible manner, independent of time and location, via digital media:

In summary, it can be stated that the media structure or the form of communication of digital learning is characterized by

- a decentralized poly-directional (several authors can communicate dialogically with each other) dimension.

- by a decentralized polyphonic (several authors can work synchronously on texts) dimension.

Digital forms of communication and learning possibilities also change the didactic possibilities (Sharples/Taylor/Vavoula (2005). Collaborative applications can also be used for this purpose, and e-tools have been increasingly developed since the early 2000s.

\section{Diversity-sensitive didactics with digital media - it is all about attitude.}

Computer code enables new communication processes. With the social dimension of the digital media of network media, new forms of shared thought arise. Within this context, the research community can be organized through digital media and thus enables a spatially and temporally decentered structure: According to diversity-sensitive approaches, this requires...

- The same opportunities for dialogue and participation and

- the same chances of interpretive and argumentative quality (cf. Habermas 1983).

Against the background of these considerations of communication theory in educational contexts, the following key points of diversity-sensitive higher education didactics with digital media can be identified. These points, in turn, require didactic skills and abilities, which the competence model formulates.

- Stakeholders should be provided with occasions to (further) develop intrinsic curiosity in a social context. (Sociocompetence)

- This social context should be characterized by a dialogic communication culture and use the polyphonic and poly-directional potential of digital media for this purpose. (Methodological competence) 
- When dealing with media through media, educators should act as maieuticc companions and enable structured openness. (Methodological competence \& professional competence)

- The cognitive goal underlying intrinsic motivation should not be restricted by media inclusions or role expectations resulting from social categories. (Methodological competence, social competence \& professional competence).

These abstract cornerstones of a diversity-sensitive, digitally supported university teaching can be systematically operationalized by criteria for educational practice: In the context of the conception of teaching/learning scenarios, must ensure that its socio-technical didactic infrastructure is in place:

- Can poly-directional and polyphonic digital tools such as Diigolet (research \& annotation tool), Authorea (collaborative writing tool) or WordPress be sensibly used?

- Are the dialogic potentials of these digital tools appropriately didacticized through appropriate tasks/educational offerings? Can students enter into a dialogical exchange through the tasks/educational offerings? Digitally based peer review formats are recommended for this purpose.

- Have students been taught strategies for critical reflection in the context of digitally supported dialogic communication in advance? Our own teaching/learning experience has shown that such communication competence cannot be assumed. Therefore, it is advisable to provide an application-oriented exercise in critical interaction in the form of a short workshop (cf. Kergel/Heidkamp 2015 for a practical perspective).

\section{Conclusion}

An area of encounter unfolds in the teaching process where actors with diverse socioeconomic and socio-cultural life experiences come together. For contemporary university teaching in the digital age, this encountering diversity in the educational space of higher education is both - an opportunity and a challenge.

Despite all (power-)structural frameworks, there is the potential of intervention, of shaping the social dynamics that unfold in higher education teaching. And it is precisely the space of higher education that is predestined to critically reflect on these practical events in the sense of a "theory of practice' relationship using scientific strategies and digitally supported, methodologically guided, and to substantiate them in a value-oriented way.

In the reflection of university teaching, two dimensions of diversity sensitivity are in the foreground:

- Power-analytical dimension of diversity sensitivity: How are hierarchies and dependency relationships, power structures and power relations established through the construction of social identity?

- Intervention level/ethical dimension of habitus and diversity sensitivity: How can exclusion processes and discrimination dynamics be counteracted?

Especially the digitally based interplay between theoretical foundation and application-oriented orientation of the reflections for action strategies of a and diversity-sensitive teaching opens a dialogical space. 
But also, this competence model and its epistemological basis can be critically problematized. Thus, the notion of learning and critical self-reflection and collaborative learning is to be situated in the context of Western epistemology. The critically reflecting individual remains the starting point for a reflection on diversity-sensitive handling of digital media. Therefore, this formulated competency model can only represent a Western reconstruction of one's handling of diversity in the context of digitization and university teaching. However, such a contribution to a cross-cultural epistemology of intercultural learning cannot be made.

\section{Literature}

Barlow, J. P. (1996). A Declaration of the Independence of Cyberspace URL: https://www.eff.org/de/cyberspace-independence. 23. August 2017.

Bouffier, A., Kehr, P., Lämmerhirt, M., \& Leicht-Scholten, C. (2014). Spätes Erwachen an deutschen Hochschulen: Die „Entdeckung" der Lehre und Berücksichtigung von Gender und Diversity. In C. Tomberger (Hrsg.), Gender- und Diversity-Kompetenzen in Hochschullehre und Beratung: Institutionelle, konzeptionelle und praktische Perspektiven (S. 53-68). Hildesheim: Universitätsverlag Hildesheim.

Derrida, J. (2002). The future of the profession or the university without condition (thanks to the 'Humanities,' what could place tomorrow. In T. Cohen (Eds.), Jacques Derrida and the Humanities. A critical Reader (pp. 26-57). Cambridge: Cambridge University Press.

Hahm, E. (2015). Diversity-Kompetenz im Bereich der Hochschullehre - Ein zentraler Baustein hochschuldidaktischer Lehrkompetenz. In Greifswalder Beiträge 2/2015, 7-21.

Kergel, D. \& Heidkamp, B. (2015). Forschendes Lernen mit digitalen Medien. Ein Lehrbuch. \#theorie \#praxis \#evaluation. Münster: Waxmann.

Kergel, D., Heidkamp, B. (2018). E-Inclusion - Diversitätssensibler Einsatz digitaler Medien. Überlegungen zu einer bildungstheoretisch fundierten Medienpädagogik. Bielefeld: Bertelsmann.

Lummerding, S. (2014), Diversifizieren. Zur Interrelation der Produktion von Wissen und der Produktion von Differenz. In D. Heitzmann \& U. Klein (Hrsg.), Diversity konkret gemacht. Wege zur Gestaltung von Vielfalt an Hochschulen (S. 45-60). Weinheim: Beltz/Juventa.

The Mentor (2004). The Hacker Manifesto. The Conscience of a Hacker. URL: http://www.itacademy.cc/article/1375/Das+Manifest+von+The+Mentor.html. Zuletzt aufgerufen: 1. September 2017. 